\title{
Design And Application Of Individuals And Moving Range Control Charts
}

Neil B. Marks, Miami University, USA

Timothy C. Krehbiel, Miami University, USA

\begin{abstract}
We evaluate the design of individuals and moving range charts through extensive simulations. Via a SAS program using 8000 replications, average run length is assessed for several shifts in process mean and variation. From these computations recommendations are made concerning when to use the individuals chart only, when to use a combined individuals and moving range chart, and the optimal design parameters when the combined approach is used. The paper includes discussion, recommendations, and examples concerning the monitoring of accounting data.
\end{abstract}

Keywords: statistical process control, individuals control charts, moving range

\section{INTRODUCTION}<smiles>c1ccccc1</smiles>
ome processes are such that forming subgroups is impossible or undesirable. For example, ongoing accounting data such as weekly, monthly, or quarterly sales totals are impossible to subgroup. In these cases, individual measurements are typically plotted in an individuals chart, sometimes called an X chart. Sometimes, the moving range (i.e., the difference between the current period and the previous period) is plotted in a moving range chart, known as an MR chart, and presented in combination with the individuals chart (which situation we shall call a combination chart or an XMR). In general, the $\mathrm{X}$ and MR portions are used to monitor the process mean and variability, respectively. On other occasions, the individuals chart is used alone. There is much disagreement as to whether the individuals chart alone or an XMR is best. Moreover, if the XMR is employed, there is the practical matter of the design of the chart, i.e., what combination of control limits is optimal.

Leading textbooks (e.g., Montgomery, 2009) often suggest an XMR but raise doubt about the usefulness of the MR portion. Practitioner-oriented publications often use XMR (e.g., Conklin, 2002) but fail to mention the ongoing debate over the design of the XMR, or if the MR portion should be included at all.

\section{MONITORING WEEKLY SALES}

Weekly sales (in thousands of dollars) for Company A are found in Table 1. The mean and standard deviation of weekly sales are 25 and 3, respectively. Figure 1 illustrates the use of an XMR with 3-sigma control limits. The process is deemed to be in control since both the $\mathrm{X}$ portion and the MR portion of the chart are in control.

As a second example, consider the weekly sales (in thousands of dollars) for Company B, also located in Table 1. Again, the mean and standard deviation of weekly sales are 25 and 3, respectively. The XMR chart in Figure 2 indicates an out-of-control process. In week 18, the sales total of 35 is above the upper control limit, and the moving range of 10, the difference between 35 and 25, is also above its upper control limit. This illustration of both the $\mathrm{X}$ and MR signaling an out-of-control situation at the same time is not unusual; in fact, it is quite common. When an individual value is large enough, or small enough, to be outside the limits, it usually produces a moving range value above the upper control limit. Thus, the value of including the MR portion with the X portion is highly debatable. 
Table 1: Weekly Sales (in thousands of dollars) used in XMR Charts

\begin{tabular}{ccc}
\hline Week & Company A & Company B \\
\hline 1 & 25 & 25 \\
2 & 22 & 22 \\
3 & 24 & 24 \\
4 & 29 & 29 \\
5 & 27 & 27 \\
6 & 22 & 22 \\
7 & 24 & 24 \\
8 & 27 & 27 \\
9 & 27 & 27 \\
10 & 24 & 24 \\
11 & 25 & 25 \\
12 & 24 & 24 \\
13 & 25 & 25 \\
14 & 22 & 22 \\
15 & 25 & 25 \\
16 & 24 & 24 \\
17 & 25 & 25 \\
18 & 25 & 35 \\
19 & 29 & 29 \\
20 & 25 & 25 \\
\hline
\end{tabular}

Figure 1: In Control Process Monitored with 3-Sigma Control Limits

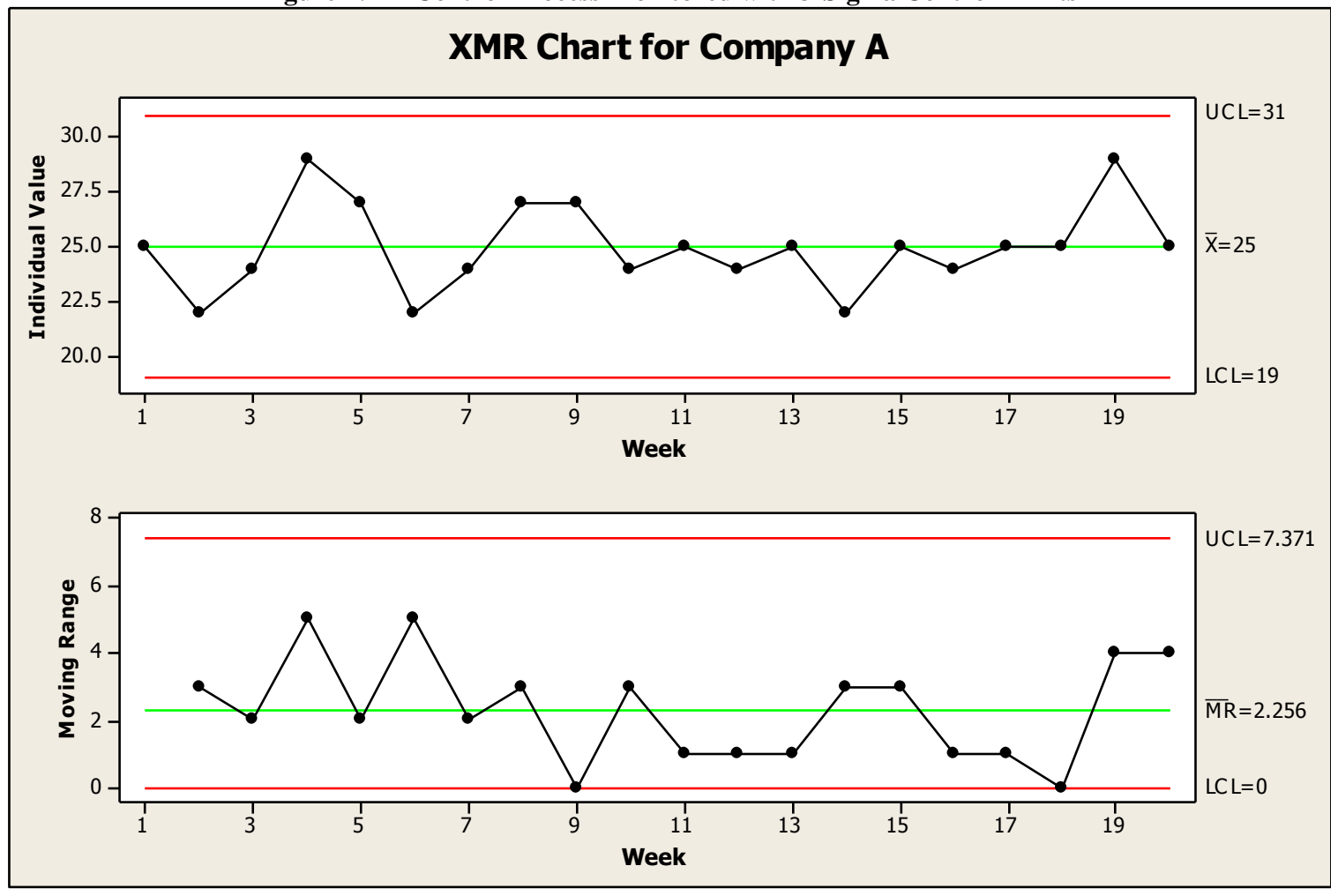


Figure 2: Out of Control Process Monitored with 3-Sigma Control Limits

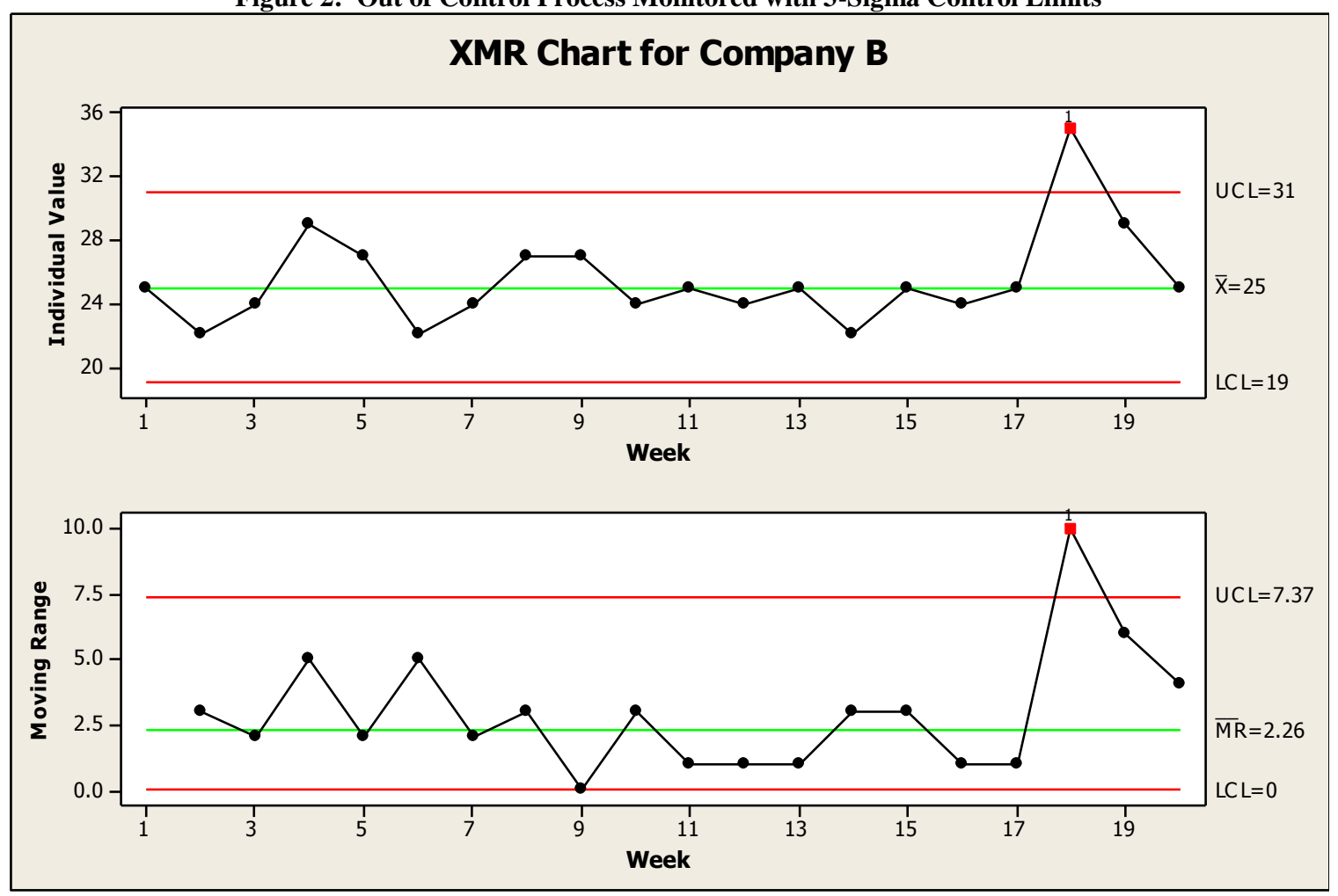

\section{LITERATURE REVIEW}

Although originally designed for manufacturing data, the application of control charts for accounting data has become relatively common in the last 20 years. Krehbiel, Havelka, and Scharfenort (2007) list five major areas where transactional processes lend themselves to control charts: financial reporting, internal auditing, external auditing, tax accounting and business operations. Other applications of control charts in accounting are found in Reeve and Philpot (1988), Roth (1990), Bruch (1994), Long, Castellano, and Roehm (2002), Davies (2004) and Grabski (2004). Dull and Tegarden (2004) argue that use of control charts on accounting data will become more common as companies increase the frequency of reporting.

Snee (2004) and Krehbiel, Havelka, and Scharfenort (2007) put forth the argument that control charts in financial and accounting functions will become even more common as more companies adopt Six Sigma quality initiatives. Many authors, including Neuschler-Fritsch and Norris (2001), Friedman and Gitlow (2002), and Rudisill and Clary (2004 \& 2005) discuss accountants' roles and responsibilities in successful Six Sigma projects. Case studies involving successful accounting applications include the elimination of inefficiencies in an accounts payable process (Brewer and Bagranoff, 2004) and improvements to the quarterly financial reporting process (Brewer and Eighme, 2005; Krehbiel, Eighme \& Cottell, 2009). Jones and Hain (2005) set up control charts to monitor key performance indicators (KPIs) in the control stage of a Six Sigma project aimed at reducing obsolete inventory in the materials management branch of a public works facility, and Falton and Falton (2002) discuss the integration of Six Sigma metrics with management dashboards. Six Sigma applications concerning Sarbanes-Oxley are discussed by Hofmann (2005), Liebesman (2005), LaComb and Senturk (2006), Senturk, LaComb, Neagu and Doganaksoy (2006), and Nanda (2008). Six Sigma applications involving balanced scorecards are illustrated by Brewer (2004) and Nilakantasrinivasan and Nair (2005).

Virtually all the applications mentioned above involve the use of data that are impossible to subgroup, and thus lend themselves to individuals and moving range charts. In discussing control charts for individual 
measurements, Nelson $(1982,1990)$, argues strongly against the use of moving range charts, given that the moving range statistic is correlated, thus making interpretation of the chart quite difficult. Acosta-Mejia and Pignatiello (2000) point out that the correlation increases false alarms over the typical range chart for $n=2$, but conclude that an XMR can be a somewhat effective method to identify increases in dispersion. Roes, Does, and Schurink (1993) conclude that adding an MR chart can increase sensitivity to changes in variability, but this is insufficient cause for support of greater use. Similarly, Rigdon, Cruthis, and Champ (1994) conclude that the individuals chart alone is nearly as efficient as the combination chart for detecting changes in variability, and therefore also argue against using the MR chart. Trip and Wieringa (2006) conclude that many of the problems in XMR applications result from the design of the chart, but that even the best-designed XMR is only slightly better than that of an individuals chart alone and therefore advise against using an MR chart.

On the other side of the argument, Crowder (1987a, 1987b) presents significant work concerning design possibilities for XMR. Crowder's work implies that XMR charts, as opposed to individuals charts alone, should be used when there is concern about changes in variability. Amin and Ethridge (1998) as well as Adke and Hong (1997) conclude that the XMR chart does provide some additional information useful in detecting variation shifts and conclude that in some situations it should be used.

The average run length (ARL) of a control chart is the average number of time periods before an out-ofcontrol signal is observed. If the process is in control and deemed "All-OK," then the ARL should be as long as possible. For a 3-sigma control chart based on normally distributed data (e.g., the individuals chart) the All-OK ARL is approximately 370, and a combination XMR chart has an All-OK ARL of approximately 200 (see Montgomery, 2009). When the process is out of control, a short ARL is desired, i.e., the user wants to be notified as soon as possible of this condition. In general, increasing the All-OK ARL (a good thing) usually increases the out-of-control ARLs (a bad thing); therefore, optimal design setting for the chart is of great interest.

Crowder presents a computer program that allows for the design of various XMR combinations which all provide All-OK ARLs of desired length. The control limits of the XMR are defined as:
$\mathrm{UCLX}=\mu+M \sigma$ (upper bound on X chart)
$\mathrm{LCLX}=\mu-M \sigma \quad$ (lower bound on X chart)
$\mathrm{UCLR}=R \sigma \quad$ (upper bound on MR chart)
$\mathrm{LCLR}=0 \quad$ (lower bound on MR chart)

Table 2: Design of XMR Charts

\begin{tabular}{|c|c|c|c|c|c|c|}
\hline $\begin{array}{c}\text { All OK } \\
\text { ARL }\end{array}$ & X-chart only & $\begin{array}{c}\text { Very tight X } \\
\text { Very wide MR }\end{array}$ & $\begin{array}{c}\text { Tight X } \\
\text { Wide MR }\end{array}$ & Balanced & $\begin{array}{c}\text { Wide X } \\
\text { Tight MR }\end{array}$ & $\begin{array}{c}\text { Very wide X } \\
\text { Very tight MR }\end{array}$ \\
\hline $\mathbf{5 0}$ & $M=2.326$ & $M=2.33$ & $M=2.40$ & $M=2.55$ & $M=2.80$ & $M=3.30$ \\
& & $R=4.50$ & $R=3.66$ & $R=3.41$ & $R=3.28$ & $R=3.24$ \\
\hline $\mathbf{1 0 0}$ & $M=2.576$ & $M=2.58$ & $M=2.65$ & $M=2.80$ & $M=3.00$ & $M=3.50$ \\
& & $R=5.00$ & $R=4.04$ & $R=3.77$ & $R=3.67$ & $R=3.60$ \\
\hline $\mathbf{2 5 0}$ & $M=2.878$ & $M=2.88$ & $M=2.95$ & $M=3.10$ & $M=3.30$ & $M=3.80$ \\
& & $R=5.00$ & $R=4.47$ & $R=4.22$ & $R=4.11$ & $R=4.05$ \\
\hline $\mathbf{3 7 0}$ & $M=3.000$ & $M=3.00$ & $M=3.10$ & $M=3.20$ & $M=3.40$ & $M=3.80$ \\
& & $R=6.00$ & $R=4.57$ & $R=4.40$ & $R=4.29$ & $R=4.23$ \\
\hline $\mathbf{5 0 0}$ & $M=3.090$ & $M=3.09$ & $M=3.20$ & $M=3.30$ & $M=3.50$ & $M=4.00$ \\
& & $R=6.00$ & $R=4.67$ & $R=4.53$ & $R=4.42$ & $R=4.36$ \\
\hline $\mathbf{7 5 0}$ & $M=3.209$ & $M=3.21$ & $M=3.30$ & $M=3.45$ & $M=3.60$ & $M=4.00$ \\
& & $R=6.00$ & $R=4.88$ & $R=4.66$ & $R=4.59$ & $R=4.55$ \\
\hline $\mathbf{1 0 0 0}$ & $M=3.291$ & $M=3.29$ & $M=3.40$ & $M=3.50$ & $M=3.65$ & $M=4.00$ \\
& & $R=6.50$ & $R=4.96$ & $R=4.82$ & $R=4.72$ & $R=4.65$ \\
\hline
\end{tabular}

X-chart: (LCL, UCL) $=\mu \pm M \sigma$, MR-chart: $\mathrm{LCL}=0, \mathrm{UCL}=R \sigma$ 
For each ARL considered, various combinations of $M$ and $R$ can be used. Crowder (1987a, p. 101) concludes that in the selection of $M$ and $R$ (step one in his design procedure), "If possible changes in the process mean are of primary concern, choosing the combination from step one with smallest $M$ will yield a control scheme with smallest ARL shifts from nominal in $\mu$. Similarly, if possible changes in the process standard deviation are of primary concern, choosing the combination from step one with smallest $R$ will provide the greatest sensitivity to changes in $\sigma$." Many of the design combinations discussed in Crowder are reproduced in Vardeman and Jobe (1999) and included here in Table 2. (We add a column to Table 2, the X-chart only case, to give added perspective and to help decide if the MR portion is needed at all.) Vardeman and Jobe concur with Crowder that the columns on the left-hand side are best for when the major concern is detecting a change in the mean, and the columns on the right-hand side are best for when the major concern is detecting an increase in variability.

\section{STUDY DESIGN}

Each of the ARLs produced in this study was generated by 8000 replications of a simulation model executed by a SAS program, whose logic is as follows. For given $M$ and $R$ and arbitrarily specified (without loss of generality) $\mu$ and $\sigma$ (50 and 10, respectively), control limits for the associated X and MR charts are computed:

$\mathrm{UCLX}=50+10 \mathrm{M}$ (upper bound on $\mathrm{X}$ chart)

LCLX $=50-10 \mathrm{M}$ (lower bound on X chart)

$\mathrm{UCLR}=10 \mathrm{R} \quad$ (upper bound on MR chart)

$\mathrm{LCLR}=0 \quad$ (lower bound on MR chart)

Then the generation of 8000 ARLs is initiated. For shifts in $\sigma$, the standard deviation (10) is multiplied by either1.5, 2 , or 2.5 , known as $\lambda$. Shifts in $\mu$ are achieved by adding $10 \mathrm{k}(\mathrm{k}=0.5,1,1.5$, or 2$)$ to the mean $(50)$. In other words, $\mathrm{k}$ is the shift of the mean in standard deviation units, and $\lambda=\sigma^{\prime} / \sigma$, where $\sigma^{\prime}$ is the new standard deviation, represents the relative increase in process variation. A succession of random observations from a normal distribution is produced according to the formula $\mathrm{X}=\mu^{*}+\mathrm{z}\left(\sigma^{*}\right)$, where $\mu^{*}$, and $\sigma^{*}$ refer to the shifted values just described, and $\mathrm{z}$ comes from the SAS function RANNOR. Examples of $X$ are $55+10 \mathrm{z}(\mathrm{k}=0.5)$ and $50+20 \mathrm{z}(\lambda=2.0)$. The moving range (MR), the absolute difference between two adjacent observations, is computed, and for a given replication, run length (RL) is established if either MR > UCLR or X < LCLX or X > UCLX. Through PROC MEANS the mean (ARL) and standard deviation of the 8000 simulated run lengths are found.

The appropriate number of replications for a study may be set as that value which achieves a satisfactorily small relative error in the estimation of the critical output, that is, half-width of the estimating confidence interval divided by the mean. In this case the standard deviation of RL is always equal to or just below the mean, so a sample size of 8000 could always produce a relative error in the vicinity of 0.02 in every case, judged to be an indicator of excellent precision in every case. ${ }^{1}$

\section{RESULTS}

Table 3 shows ARLs using the format of Vardeman and Jobe's chart for various settings of $\mathrm{k}$ and $\lambda$, plus the X-chart only case. As expected, the ARL relative to $\mathrm{k}$ rises from left to right since detection of the shift becomes increasingly difficult. There is little distinction to be observed between the X-chart only and Very Tight X/Very Wide MR cases. On the far right (Very Wide X/Very Tight MR), the simulated ARLs are approximately the AllOK ARLs.

By contrast, ARL relative to shifts in variability follows a parabolic path from left to right, ending with values approximating those of an MR chart only since at that point the control limits on the $\mathrm{X}$ chart are of little consequence. The increase in ARLs in the far right columns compared to the middle columns of Table 3 is both counter intuitive and contradictory to Crowder's assertion. Our results indicate that the $\mathrm{X}$ chart has become so wide at this point that it loses almost all ability to detect increases in process variation while the tighter MR chart is only slightly more sensitive. The result is that these combination charts are actually worse at detecting an increase in process variation. For example, when using an All-OK ARL of 50, the Very Wide X/Very Tight MR design detects a doubling of the process variation in 4.05 subgroups on average, while the balanced design takes only an average of 
3.49 subgroups. Moreover, the Very Wide X/Very Tight MR design is extremely slow at detecting changes in the mean. Of great interest is that the designs in the last three columns (Balanced, Wide X/Tight MR, and Very Wide X/ Very Tight MR) are statistically equal to or worse than the first three columns for all 21 combinations of ARLs and increased variability the study investigated. ${ }^{2}$

Table 3: ARLs for $\mathrm{k}=(0.5,1,2)$ and $\lambda=(1.5,2,2.5)$

\begin{tabular}{|c|c|c|c|c|c|c|c|c|c|c|c|c|}
\hline \multirow{2}{*}{$\begin{array}{c}\text { All } \\
\text { OK } \\
\text { ARL } \\
50\end{array}$} & \multicolumn{2}{|c|}{ X-chart only } & \multicolumn{2}{|c|}{$\begin{array}{c}\text { Very tight } X \\
\text { Very wide } M R\end{array}$} & \multicolumn{2}{|c|}{$\begin{array}{c}\text { Tight X } \\
\text { Wide MR }\end{array}$} & \multicolumn{2}{|c|}{ Balanced } & \multicolumn{2}{|c|}{$\begin{array}{c}\text { Wide X } \\
\text { Tight MR }\end{array}$} & \multicolumn{2}{|c|}{$\begin{array}{c}\text { Very wide } X \\
\text { Very tight } M R\end{array}$} \\
\hline & 27.46 & 8.14 & 27.90 & 7.93 & 29.44 & 7.54 & 34.76 & 7.51 & 41.21 & 7.79 & 48.63 & 8.58 \\
\hline & 10.69 & 4.07 & 10.90 & 3.74 & 12.01 & 3.47 & 15.14 & 3.49 & 21.89 & 3.65 & 39.17 & 4.05 \\
\hline & 2.72 & 2.86 & 2.73 & 2.49 & 2.88 & 2.33 & 3.44 & 2.34 & 4.65 & 2.42 & 9.65 & 2.58 \\
\hline 100 & 50.03 & 11.50 & 50.32 & 11.32 & 54.60 & 10.51 & 65.23 & 10.60 & 79.72 & 11.13 & 96.13 & 12.04 \\
\hline & 17.34 & 5.01 & 7.49 & 4.71 & 19.61 & 4.38 & 25.51 & 4.37 & 36.39 & 4.54 & 71.64 & 5.01 \\
\hline & 3.59 & 3.34 & 3.61 & 2.99 & 3.91 & 2.72 & 4.72 & 2.71 & 6.28 & 2.82 & 14.45 & 3.05 \\
\hline 250 & 111.09 & 18.11 & 109.11 & 17.91 & 123.78 & 16.30 & 153.84 & 16.56 & 189.46 & 17.26 & 250.90 & 19.19 \\
\hline & 32.96 & 6.62 & 33.15 & 6.31 & 38.71 & 5.83 & 52.21 & 5.80 & 77.79 & 6.10 & 174.18 & 6.73 \\
\hline & 5.27 & 3.99 & 5.29 & 3.64 & 5.87 & 3.31 & 7.33 & 3.34 & 10.28 & 3.46 & 26.75 & 3.83 \\
\hline 370 & 155.48 & 21.85 & 155.55 & 21.75 & 185.55 & 19.63 & 212.13 & 19.66 & 271.89 & 20.75 & 376.90 & 22.67 \\
\hline & 43.99 & 7.40 & 43.96 & 7.18 & 54.80 & 6.52 & 67.35 & 6.50 & 103.86 & 6.77 & 217.24 & 7.48 \\
\hline & 6.35 & 4.33 & 6.35 & 4.04 & 7.36 & 3.60 & 8.70 & 3.62 & 12.41 & 3.77 & 27.32 & 4.06 \\
\hline 500 & 200.37 & 25.10 & 200.24 & 24.96 & 243.80 & 22.57 & 284.49 & 22.85 & 369.48 & 23.94 & 504.10 & 26.86 \\
\hline & 53.89 & 8.05 & 55.00 & 7.79 & 70.71 & 7.12 & 86.59 & 7.19 & 139.78 & 7.52 & 470.48 & 8.31 \\
\hline & 7.26 & 4.59 & 7.25 & 4.27 & 8.72 & 3.85 & 10.35 & 3.87 & 14.91 & 4.03 & 43.33 & 4.47 \\
\hline 750 & 288.78 & 30.34 & 286.87 & 30.08 & 342.90 & 27.38 & 433.79 & 27.42 & 528.72 & 28.70 & 749.70 & 32.20 \\
\hline & 73.04 & 9.07 & 72.92 & 8.75 & 89.93 & 8.00 & 128.79 & 8.09 & 189.63 & 8.38 & 334.37 & 9.31 \\
\hline & 8.92 & 4.98 & 8.88 & 4.60 & 10.36 & 4.16 & 13.67 & 4.20 & 18.27 & 4.37 & 42.19 & 4.79 \\
\hline 1000 & 372.56 & 34.72 & 365.86 & 34.60 & 458.75 & 31.36 & 549.77 & 31.73 & 660.89 & 32.53 & 997.90 & 35.33 \\
\hline & 89.21 & 9.85 & 90.96 & 9.61 & 116.72 & 8.70 & 149.91 & 8.78 & 215.54 & 9.06 & 426.29 & 9.80 \\
\hline & 10.14 & 5.27 & 10.19 & 4.97 & 12.49 & 4.41 & 14.97 & 4.45 & 20.34 & 4.57 & 43.19 & 4.97 \\
\hline
\end{tabular}

The first column of numbers in a cell represent $\mathrm{k}=0.5,1$, and 2 , respectively, when $\lambda=\sigma / \sigma=1$, and the second column of numbers in a cell represent $\lambda=\sigma^{\prime} / \sigma=1.5,2$, and 2.5 , respectively, when $\mathrm{k}=0$.

\section{RECOMMENDATIONS}

The moving range chart alone is seen to be of little value since its benefit, a marginal ability to detect shifts in process variation, is overwhelmed by a substantial insensitivity to shifts in the mean. Further, in contrast to suggestions made by other researchers, we find that pertaining to detection of increased process variation, the combined charts having narrow moving range control limits are actually inferior to those with wider limits. Based on the results of our simulations, we offer the following recommendations:

1. An X-chart only is the most sensitive to changes in the mean. The chart is also relatively sensitive to increases in variability.

2. Adding a MR-chart decreases the chance of detecting a change in the mean.

3. Adding a MR-chart slightly increases the chance of detecting a change in the process variation.

4. As a direct result of 1-3, there is very little value from using the MR-chart, since the substantial loss of sensitivity to mean changes overshadows the slight gain in sensitivity to variation changes.

5. In specific instances where the analyst is more concerned with increases in variation than mean shifts, the Tight X/Wide MR combinations of an XMR chart are appropriate.

6. Combinations on the right-hand-side of Table 2 or Table 3 (e.g., Balanced, Wide X/Tight MR, Very Wide $\mathrm{X} /$ Very Tight MR) are actually equal to or worse at detecting changes in the process variation that those charts in the middle. Therefore, we recommend that these three columns never be used.

7. Since accounting data are typically collected weekly, monthly, or quarterly, the All-OK ARLs should be much shorter than those typically used in the data-rich manufacturing environment. If collection occurs 
once a month, a false alarm every 370 time periods equates to one about every 31 years, whereas, a frequency of four collections each hour produces one about every 4 days.

8. In the common case that only an X chart is employed, changes in the mean and increases in variation will be detected. The analyst, however, needs to investigate the nature of the out-of-control signal to determine if the process is experiencing a change in the mean or an increase in variation. The two examples that follow illustrate the concept.

Table 4: Weekly Sales ( in thousands of dollars) used in X Charts

\begin{tabular}{ccc}
\hline Week & Company C & Company D \\
\hline 1 & 27 & 27 \\
2 & 23 & 23 \\
3 & 24 & 24 \\
4 & 27 & 27 \\
5 & 23 & 23 \\
6 & 23 & 23 \\
7 & 25 & 25 \\
8 & 24 & 24 \\
9 & 27 & 27 \\
10 & 27 & 27 \\
11 & 22 & 22 \\
12 & 24 & 26 \\
13 & 35 & 31 \\
14 & 23 & 22 \\
15 & 28 & 26 \\
16 & 27 & 30 \\
17 & 28 & 23 \\
18 & 25 & 19 \\
19 & 25 & 28 \\
20 & 23 & 23 \\
\hline
\end{tabular}

Figure 3. Out of Control Signal Due to a Change in the Mean

\section{Chart for Company C}

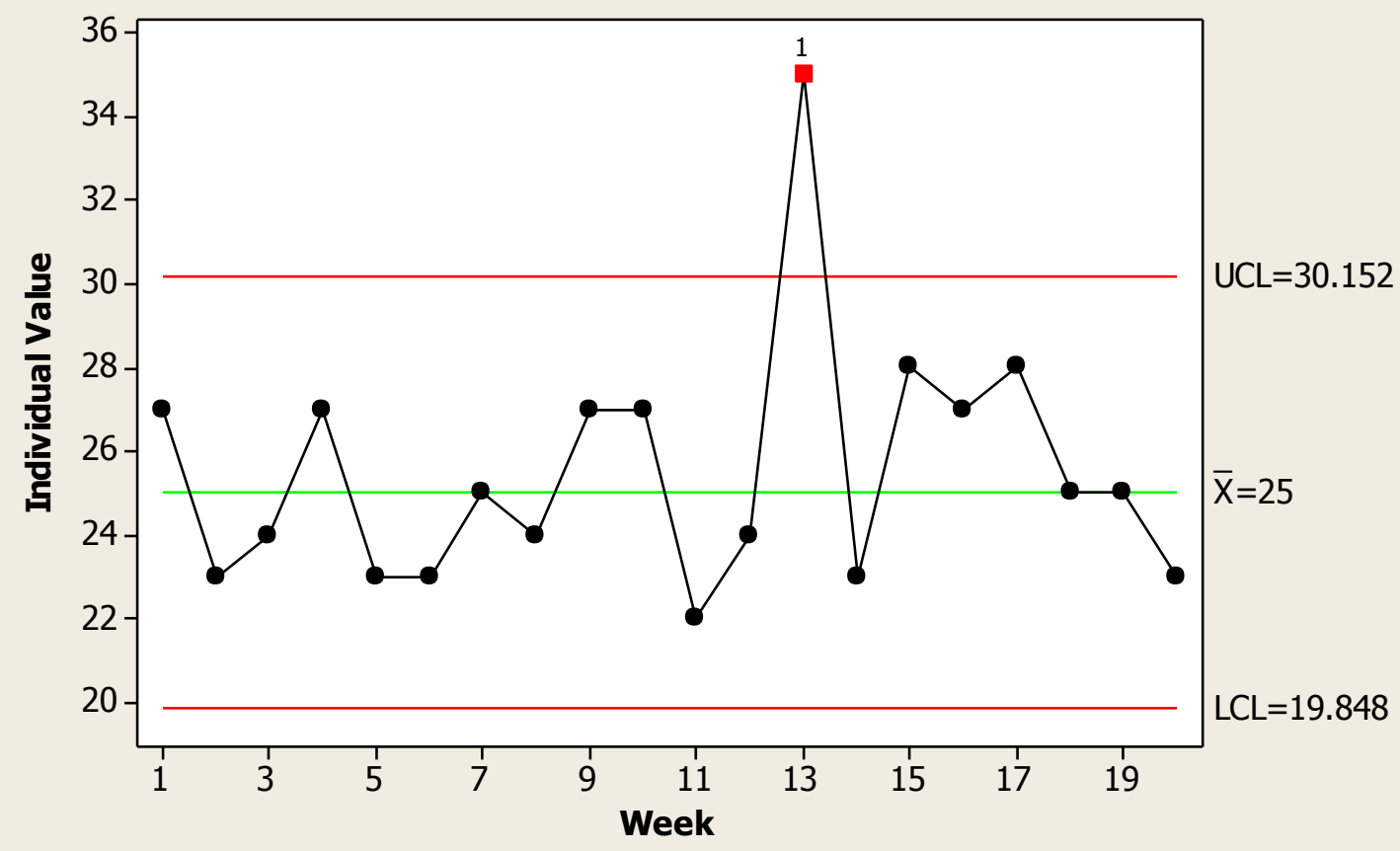


Figure 4: Out of Control Signal Due to an Increase in Variation

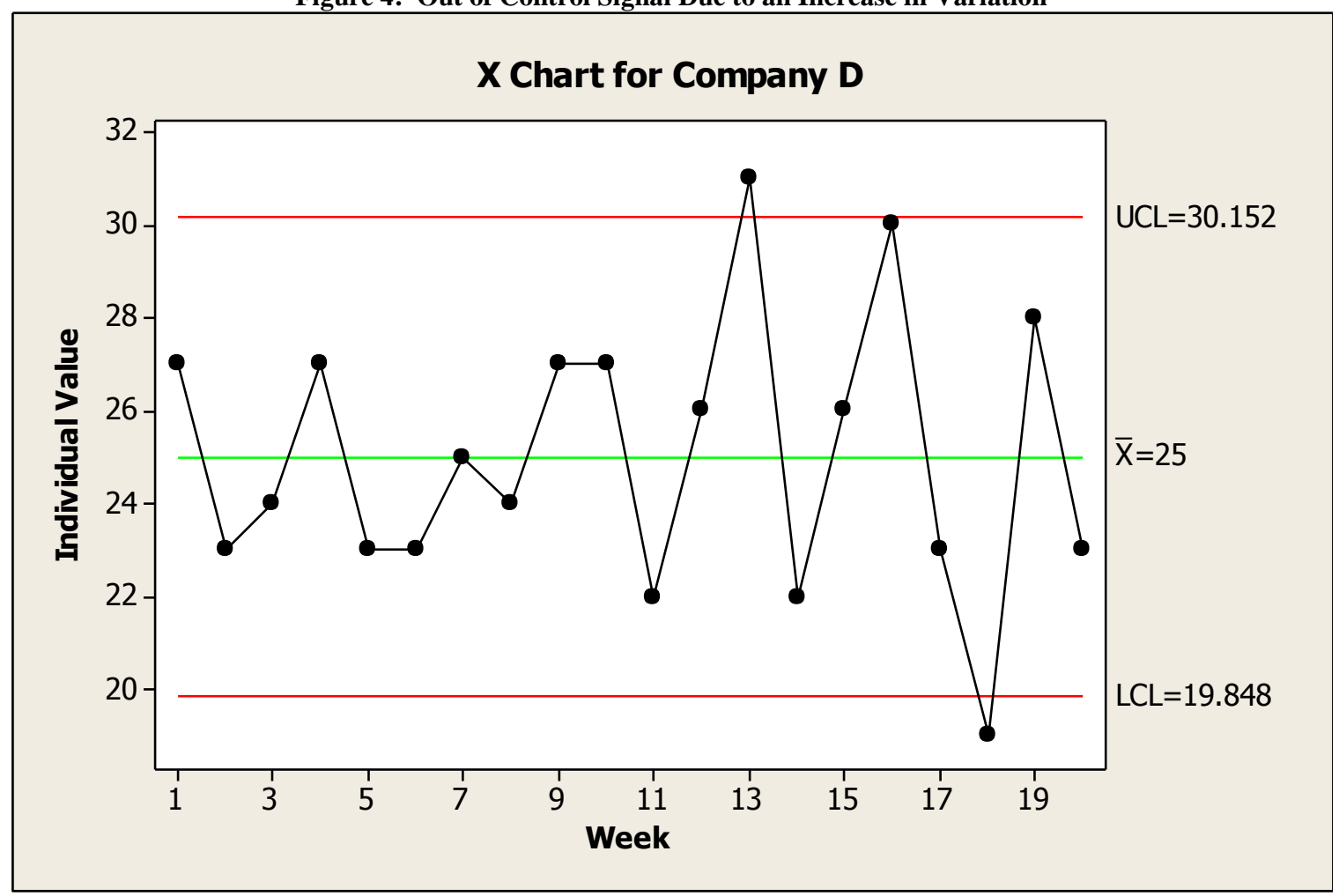

\section{EXAMPLES}

Company $\mathrm{C}$ designs an X chart with an All-OK ARL of 100. The mean and standard deviation of weekly sales are 25 and 3 , respectively. Thus the upper control limit is placed 2.576 sigma above the mean and the lower control limit 2.576 sigma below the mean. The sales for 20 weeks are located in Table 4 and the control chart appears in Figure 3. The out-of-control signal is produced by a one-time increase in central tendency, and the variation around the center line appears not to increase before or after the spike.

Company D designs an X chart with an All-OK ARL of 100. Once again, the mean and standard deviation of weekly sales are 25 and 3, respectively, and the control limits are the same as above. The data are located in Table 4 and the control chart in Figure 4 indicates an out-of-control signal. In this example, the variability around the center line approximately doubles after week 10 . Although the X chart picked up the out-of-control condition, the mean of the last 10 days was still 25 . The increased variability was detected because of the tight control limits on the $\mathrm{X}$ chart made possible by omitting the MR chart.

\section{SUGGESTIONS FOR FUTURE RESEARCH}

Although individuals and moving range charts are easily designed and implemented and relatively effective, recent advancements in process monitoring in the manufacturing sector using highly sophisticated techniques may be adaptable to accounting data. In particular, exponentially weighted moving average charts with a fast-initial-response (FIR) enhancement and the similarly constructed cumulative sum chart with an FIR enhancement warrant investigation. 


\section{NOTES}

1. The relative error is calculated as follows for a $95 \%$ confidence interval:

$(1 /$ mean $) \cdot((1.96 \cdot$ stdev $) /(\sqrt{ } 8000))$.

As examples, in column 5 of Table 3 with in-control ARL of 1000 and lambda of 2.5, the mean 4.572 and standard deviation 4.513 give a relative error of 0.0216. In column1 (in-control ARL equal to 250 and lambda of 1.5), the mean 18.110 and standard deviation 17.752 produced a relative error 0.0215 . In column 3 (in-control ARL equal to 50 and $\mathrm{k}=1$ ), the mean 12.013 and standard deviation 11.545 give a relative error 0.0211 .

2. Hypothesis tests comparing ARLs at the 5\% level of significance were conducted. Column 3 (Tight X, Wide MR) was found indistinguishable from column 4 (Balanced), i.e., the null hypothesis of equal ARLs was not rejected in all 21 cases. Column 5 (Wide X, Tight M) was found to be inferior to Column 3, i.e., in all 21 cases the null hypothesis was rejected. Likewise, Column 6 (Very Wide X, Very Tight M) was found to be inferior to Column 3.

\section{AUTHOR INFORMATION}

Neil B. Marks earned a B. S. (Applied Mathematics) and M. B. A. at Washington University in St. Louis and a Ph. D. (Management Science) at The Ohio State University. He has taught at several American universities, the last being Miami University since 1985, holding now the rank of Associate Professor of Decision Sciences. His research interests lie in applied statistics and simulation of random processes. His work has appeared in International Journal of Production Research, Journal of the Operational Research Society, Communications in Statistics, Production and Inventory Management Journal, Decision Sciences Journal of Innovative Education, and Journal of Applied Statistics.

Timothy C. Krehbiel earned a B. A. (History) at McPherson College and a M.S. (Statistics) and Ph. D. (Statistics) at The University of Wyoming. He has taught at Miami University since 1990, holding now the rank of Professor and Endres Faculty Fellow. His research interests include statistical process control and six sigma quality. His work has appeared in Quality Management Journal, International Journal of Production Research, Communications in Statistics, and Journal of Purchasing and Supply Management. He is also the co-author of three textbooks: Basic Business Statistics, Business Statistics a First Course, and Statistics for Managers Using Microsoft Excel.

\section{REFERENCES}

1. 1.Acosta-Mejia, C. A., Pignatiello, Jr., J. J. (2000). Monitoring dispersion without subgrouping. Journal of Quality Technology 32(2):89-102.

2. Adke, S. R., Hong, X. (1997). A supplementary test based on the control chart for individuals. Journal of Quality Technology 29(1):16-20.

3. Amin, R. W., Ethridge, R. A. (1998). A note on individual and moving range control charts. Journal of Quality Technology 30(1):70-74.

4. Brewer, P. C. 2004. Six Sigma helps a company create a culture of accountability. Journal of Organizational Excellence (Summer) 45-59.

5. Brewer, P. C. and N. A. Bagranoff. 2004. Near zero-defect accounting with Six Sigma. Journal of Corporate Accounting and Finance (January/February) 67-72.

6. Brewer, P. C. and J. E. Eighme. 2005. Using Six Sigma to improve the finance function. Strategic Finance (May) 27-33.

7. Bruch, N. M. 1994. Using control charts to help manage accounts receivable. Healthcare Financial Management 48(7):44-48.

8. Conklin, J. D. (2002). Control charts and administration. Quality Progress 35(3):99-102.

9. Crowder, S. V. (1987a). Computation of ARL for combined individual measurement and moving range charts. Journal of Quality Technology 19(2):98-102.

10. Crowder, S. V. (1987b). A program for the computation of ARL for combined individual measurement and moving range charts. Journal of Quality Technology 19(2):103-106. 
11. Davies, M. C. 2004. Discussion of supporting continuous monitoring using control charts. International Journal of Accounting Information System 5(2):131-134.

12. Dull, R. B. and D. P. Tegarden. 2004. Using control charts to monitor financial reporting of public companies. International Journal of Accounting Information Systems 5(2):109-127.

13. Falton, D. M., and F. W. Falton. 2003. Toe the line: No more WorldComs. Quality Progress (January) 2935.

14. Friedman M. and H. Gitlow. 2002. The CPA in industry: Six Sigma primer for CPAs. The CPA Journal (November) 56-59.

15. Grabski, S. 2004. Discussion of supporting continuous monitoring using control charts. International Journal of Accounting Information Systems 5(2):129-130.

16. Hofmann, A. 2005. Two controls, one result. Quality Progress (July) 68-71.

17. Jones, E. C., and J. A. Hain. 2005. Use what you have. Six Sigma Forum Magazine 4(3):23-28.

18. Krehbiel, T. C., Eighme, J. E., and P. G. Cottell. 2009. Morgan Systems, Inc.: Application of Six Sigma to the finance function. Forthcoming in Journal of Accounting Education.

19. Krehbiel, T. C., Havelka, D., and M. Scharfenort. 2007. Process monitoring in accounting: Implementing pre-control charts. Journal of Applied Business Research.23(4):93-104.

20. 20. LaComb, C., and D. Senturk. 2006. The house that fraud built. Quality Progress (January) 52-60.

21. Liebesman, S. 2005. Mitigate SOX risk with ISO 9001 and 14001. Quality Progress (September) 91-93.

22. Long, J. A., J. F. Castellano and A. Roehm. 2002. A user friendly financial reporting system. Quality Progress (January) 60-66.

23. Montgomery, D. C. 2009. Introduction to Statistical Quality Control. New Jersey: John Wiley and Sons, Inc.

24. Nanda, V. 2008. Two are better than one. Quality Progress (June) 42-47.

25. Nelson, L. S. (1982). Control charts for individual measurements. Journal of Quality Technology 14(2):172-173.

26. Nelson, L. S. (1990). Monitoring reduction in variation with a range chart. Journal of Quality Technology 22(2):163-165.

27. Nilakantasrinivasan, N., and A. Nair. 2005. DMAIC failure modes. Six Sigma Forum Magazine 4(3):30-34.

28. Neuschler-Fritsch, D. and R. Norris. 2001. Capturing financial benefits from Six Sigma. Quality Progress (May) 39-44.

29. Reeve, J. M., and J. W. Philpot. 1988. Applications of statistical process control for financial management. Journal of Cost Management (Fall) 33-40.

30. Rigdon, S. E., Cruthis, E. N., Champ, C. W. (1994). Design strategies for individuals and moving range control charts. Journal of Quality Technology 26(4):274-287.

31. Roes, K.C.B., Does, R. J. M. M., Schurink, Y. (1993). Shewhart-type control charts for individual observations. Journal of Quality Technology 25:188-198.

32. Roth, H. P. 1990. Applications of control charts. The CPA Journal (April) 90-95.

33. Rudisill, F. and D. Clary. 2004. The management accountant's role in Six Sigma. Strategic Finance (November) 35-39.

34. Rudisill, F. and D. Clary. 2005. Six Sigma: Saving and making money. Chartered Accountant's Journal (April) 21-25.

35. Senturk, D., LaComb, C., Neagu, R. and M. Doganaksoy. 2006. Detect financial problems with Six Sigma. Quality Progress (April) 41-47.

36. Snee, R. D. 2004. Weave Six Sigma into the fabric of an organization. Quality Progress (September) 6972.

37. Trip, A., Wieringa, J. E. (2006). Individuals charts and additional tests for changes in spread. Quality and Reliability Engineering International 22:239-249.

38. Vardeman, S. B., Jobe, J. M. (1999). Statistical Quality Assurance Methods for Engineers. New York: Wiley. 